\title{
Tumorigenesis of 2-amino-3,8-dimethylimidazo[4,5-f]quinoxaline (MeIQx), but not enhancing effects of concomitant high-fat diet, on lung carcinogenesis in female $\mathbf{A} / \mathbf{J}$ mice
}

\author{
HIJIRI TAKEUCHI ${ }^{1}$, KOUSUKE SAOO ${ }^{1}$, KEIKO YAMAKAWA ${ }^{1}$, YOKO MATSUDA ${ }^{1}$, \\ MASANAO YOKOHIRA ${ }^{1}$, YU ZENG ${ }^{1}$, TOTSHIYA KUNO ${ }^{1}$, YUKARI TOTSUKA ${ }^{2}$, \\ MAMI TAKAHASHI ${ }^{2}$, KEIJI WAKABAYASHI ${ }^{2}$ and KATSUMI IMAIDA $^{1}$ \\ ${ }^{1}$ Onco-Pathology, Department of Pathology and Host-Defense, Faculty of Medicine, Kagawa University, Kagawa 761-0793; \\ ${ }^{2}$ Cancer Prevention Basic Research Project, National Cancer Center Research Institute, Tokyo 104-0045, Japan
}

Received May 13, 2009; Accepted August 21, 2009

\author{
DOI: 10.3892/ol_00000025
}

\begin{abstract}
It has been reported that 2-amino-3,8dimethylimidazo[4,5-f]quinoxaline (MeIQx) induces liver tumors and to a lesser extent lung lesions, lymphomas and leukemias in $\mathrm{CDF}_{1}$ mice. Since a number of case control studies have pointed to a positive association between fat consumption and lung cancer, we examined the lung carcinogenic potential of MeIQx treatment concomitant with a high-fat diet using female A/J mice. Groups 1 and 2 were fed a diet supplemented with MeIQx at a concentration of $600 \mathrm{ppm}$. Groups 1 and 3 received a diet containing $20 \%$ corn oil and group 4 was fed the basal diet alone. After 1 week, 10 mice in each group were sacrificed for measurement of cytochrome P450 (CYP)1A2 mRNA in the liver and lung. The remaining mice were maintained on their respective diets until termination, 32 weeks after the initial MeIQx treatment, when lung proliferative lesions were analyzed. The incidences and multiplicities of hyperplasias and adenomas in MeIQx-treated groups (groups 1 and 2) were significantly higher than in the groups without MeIQx treatment, with a significant increase in the incidences and multiplicities of adenomas + carcinomas, as well as hyperplasia + adenomas + carcinomas (lung proliferative lesions). Lung carcinomas were observed in 1 mouse in each of the MeIQx-treated groups.
\end{abstract}

Correspondence to: Dr Katsumi Imaida, Onco-Pathology, Department of Pathology and Host-Defense, Faculty of Medicine, Kagawa University, 1750-1 Ikenobe, Miki-cho, Kita-gun, Kagawa 761-0793, Japan

E-mail: imaida@med.kagawa-u.ac.jp

Abbreviations: MeIQx, 2-amino-3,8-dimethylimidazo[4,5- $f]$ quinoxaline; CYP, cytochrome P450; DiMeIQx, 2-amino -3,4,8-trimethylimidazo[4,5-f]quinoxaline; PhIP, 2-amino-1-methyl6-phenylimidazo-[4,5-b]pyridine; 4-NQO, 4-nitroquinoline 1-oxide; NAT, arylamine N-acetyltransferase; GAPDH, glyceraldehyde-3phosphate dehydrogenase; RT-PCR, reverse-transcriptase polymerase chain reaction

Key words: A/J mice, lung carcinogenesis, MeIQx
However, the high-fat diet (groups 1 and 3) did not affect the incidences or multiplicities of lung proliferative lesions. Expression levels of CYP1A2 mRNA after MeIQx treatment significantly increased $>3$-fold in livers, but no significant change was noted in the lungs, where levels were very low at $1 / 210$ and $1 / 923$ the values for livers. In conclusion, following a 32-week period, we confirmed the lung tumorigenic potential of MeIQx which possibly occurs due to proximate carcinogens activated by CYP1A2 in the liver. However, we failed to detect any influence of a high-fat diet.

\section{Introduction}

Epidemiological and experimental studies have demonstrated that heterocyclic amines generated in meat and fish cooked at high temperature are highly mutagenic and rodent carcinogenic (1-3). For example, case control studies have provided evidence that high-temperature cooked meat is associated with risk of colon $(4,5)$, breast $(6,7)$, gastric $(8)$ and lung $(9,10)$ cancer. As a heterocyclic amine, 2-amino-3,8-dimethylimidazo[4,5- $f$ ]quinoxaline (MeIQx), is associated with human lung cancer risk, whereas 2-amino-3,4,8-trimethylimidazo[4,5-f]quinoxaline (DiMeIQx) and 2-amino-1-methyl-6-phenylimidazo-[4,5-b] pyridine (PhIP) are not (11). MeIQx has been reported to induce liver and lung tumors, lymphomas and leukemias in $\mathrm{CDF}_{1}$ mice (12). Although the incidence of MeIQx-induced liver tumors was high, values for lung and hematopoetic system tumors were much lower, and in the case of lung only female patients were affected. Therefore, whether the lung is actually a target organ for MeIQx is somewhat controversial.

Since epidemiological and experimental studies have demonstrated that fat consumption is associated with cancer risk in several organs (13-17) including the lung $(10,14,18-20)$, this study investigated whether this correlation was able to modify risk in the MeIQx mouse model. A high-fat diet was previously shown to enhance the 4-nitroquinoline 1-oxide (4NQO)induction of lung tumorigenesis in mice (21). Female A/J mice which are highly susceptible to lung carcinogens were selected to investigate the relationship between the lung carcinogenic potential of MeIQx and a high-fat diet in a medium-term test. 
Table I. Final body and relative organ weights for A/J mice fed diets containing MeIQx and/or high fat.

\begin{tabular}{|c|c|c|c|c|c|c|}
\hline \multirow[b]{2}{*}{ Group } & \multirow[b]{2}{*}{ Treatment } & \multicolumn{2}{|r|}{ Final } & \multicolumn{3}{|c|}{ Organ weight } \\
\hline & & No. ${ }^{\mathrm{a}}$ & Body weight (g) & Lung $(\mathrm{g} \%)$ & Liver $(g \%)$ & Kidneys (g\%) \\
\hline 1 & MeIQx 600 ppm + high-fat diet & 20 & $32.11 \pm 3.69^{\mathrm{b}, \mathrm{c}}$ & $0.61 \pm 0.08$ & $4.24 \pm 0.33^{\mathrm{d}}$ & $1.06 \pm 0.09$ \\
\hline 2 & MeIQx 600 ppm + basal diet & 20 & $29.34 \pm 2.90$ & $0.63 \pm 0.08$ & $4.56 \pm 0.32$ & $1.13 \pm 0.07$ \\
\hline 3 & High-fat diet & 18 & $45.47 \pm 5.41^{\mathrm{e}}$ & $0.48 \pm 0.06^{\mathrm{e}}$ & $3.36 \pm 0.30^{\mathrm{f}}$ & $0.87 \pm 0.11^{\mathrm{f}}$ \\
\hline 4 & Basal diet & 19 & $30.27 \pm 5.05$ & $0.63 \pm 0.09$ & $3.84 \pm 0.38^{\mathrm{f}}$ & $1.05 \pm 0.14$ \\
\hline
\end{tabular}

${ }^{a}$ Number of mice examined. ${ }^{b}$ Mean \pm SD. ${ }^{c}$ Significantly different from group $2(\mathrm{P}<0.05)$; ${ }^{\mathrm{d}}$ significantly different from group 2 (P<0.01);

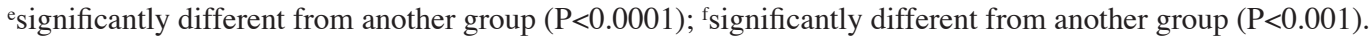

MeIQx is thought to be metabolically activated to genotoxic intermediates by CYP1A2-mediated N-hydroxylation in the liver (22,23). MeIQx then undergoes $O$-esterification catalyzed by arylamine $N$-acetyltransferase (NAT) (24). The rat and human CYP1A2 share a $75 \%$ identity in their amino acid sequences (25) and levels of CYP1A2 mRNA are increased approximately $1.5-2$-fold by treatment with MeIQx in the rat liver (26). However, CYP1A2 levels in the lung have not been assessed and were thus investigated.

\section{Materials and methods}

Chemicals. MeIQx was purchased from the Nard Institute (Osaka, Japan).

Animals. Female A/J mice (5 weeks of age), purchased from Shizuoka Laboratory Animal Center (Shizuoka, Japan), were maintained in the Kagawa University Animal Facility according to the institutional animal care guidelines. The animals were housed in polycarbonate cages with white wood chips for bedding and given free access to drinking water. Starting at 7 weeks of age, groups 1 and 2 were fed a diet supplemented with MeIQx at a concentration of $600 \mathrm{ppm}$. For groups 1 and 3 the diets contained $20 \%$ corn oil. Group 4 was fed the basal diet, CE-2 (Clea Japan Inc., Tokyo, Japan), without supplement. The mice were maintained on their respective diets and under controlled conditions of humidity $(60 \pm 10 \%)$, lighting (12-h light/dark cycle) and temperature $\left(24 \pm 2^{\circ} \mathrm{C}\right)$ until termination at week 32. Surviving mice were then sacrificed under ether anesthesia and their lungs were excised, weighted, inflated with $10 \%$ neutral-buffered formalin and carefully inspected grossly. Macroscopically detected lung nodules were counted under a stereomicroscope and each lung lobe was examined histopathologically.

Subjects for mRNA quantitation. For mRNA studies, groups of 10 mice were sacrificed after 1 week of study for lung and liver RNA isolation and quantitative analysis of CYP1A2.

RNA isolation. Total RNA was isolated from the $30 \mathrm{mg}$ of whole lung and liver tissues using RNAlater RNA Stabilization Reagent and an RNeasy Mini Kit (both from Qiagen Corp.,
Hilden, Germany). The RNA concentration was measured at an absorbance of $260 \mathrm{~nm}$. First-strand cDNA was synthesized from $400 \mathrm{ng}$ of total RNA using TaqMan Reverse Transcription Reagents (Applied Biosystems, Foster City, CA, USA), according to the manufacturer's instructions.

Quantitative real-time RT-PCR. Optimal primers and probes were purchased from the Assays-on-demand system of Applied Biosystems (ABI). The TaqMan rodent glyceraldehyde-3phosphate dehydrogenase (GAPDH) control reagent (ABI) was used for the PCR of GAPDH mRNA as an internal control. Primer sequences and TaqMan probes for CYP1A2 and GAPDH mRNA were closed because of purchasing from the Assays-on-demand system of ABI.

Quantitative real-time RT-PCR was performed with the ABI PRISM 7000 Sequence Detection System using specific primers and a TaqMan probe for CYP1A2. PCR was carried out in $50 \mu \mathrm{l}$ reaction mixtures containing $25 \mu \mathrm{l}$ of $2 \mathrm{X}$ TaqMan Universal PCR Master Mix, 50 ng of cDNA, $100 \mathrm{nM}$ of each primer and $200 \mathrm{nM}$ of TaqMan probe. Cycling conditions were: $2 \mathrm{~min}$ at $50^{\circ} \mathrm{C}, 10 \mathrm{~min}$ at $95^{\circ} \mathrm{C}$ and then 40 cycles of $15 \mathrm{sec}$ at $95^{\circ} \mathrm{C}$, followed by $1 \mathrm{~min}$ at $60^{\circ} \mathrm{C}$. PCR amplification of GAPDH mRNA was carried out as above. TaqMan PCR products were detected as an increase in fluorescence from cycle to cycle. The amplification plots of the PCR reaction were used to determine the threshold cycle $(\mathrm{Ct})$. The $\mathrm{Ct}$ value represented the PCR cycle at which an increase in reporter fluorescence $(\Delta R n)$ above the line of the optimal value was first detected. The initial copy number of the target mRNA was calculated from plots of the $\mathrm{Ct}$ against the input target quantity.

The precise amount and quality of total RNA are difficult to assess. Therefore, we quantified transcripts of the GAPDH gene as an internal control according to a quantitative RT-PCR assay. Normalization of the data was achieved by quantitating the cycle number at an arbitrary fluorescence intensity in the linear exponential phase by calculating the ratio of the cycle number of each enzyme relative to that of GAPDH.

Statistical analysis. The data for final body and relative organ weights were analyzed by Student's t-test. The incidences of lung proliferative lesions were analyzed by Fisher's exact probability test and data for multiplicity by Student's t-test. 

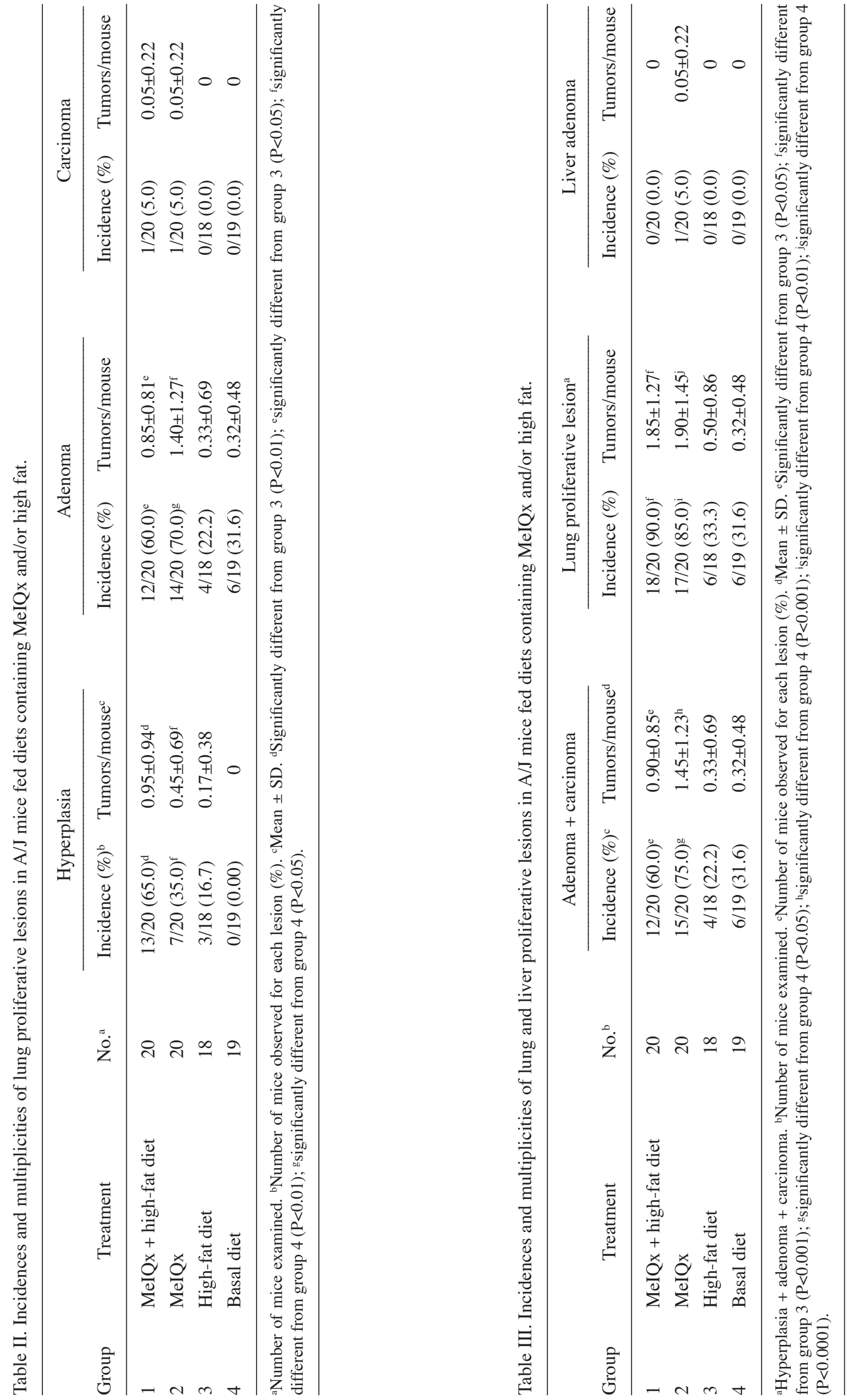

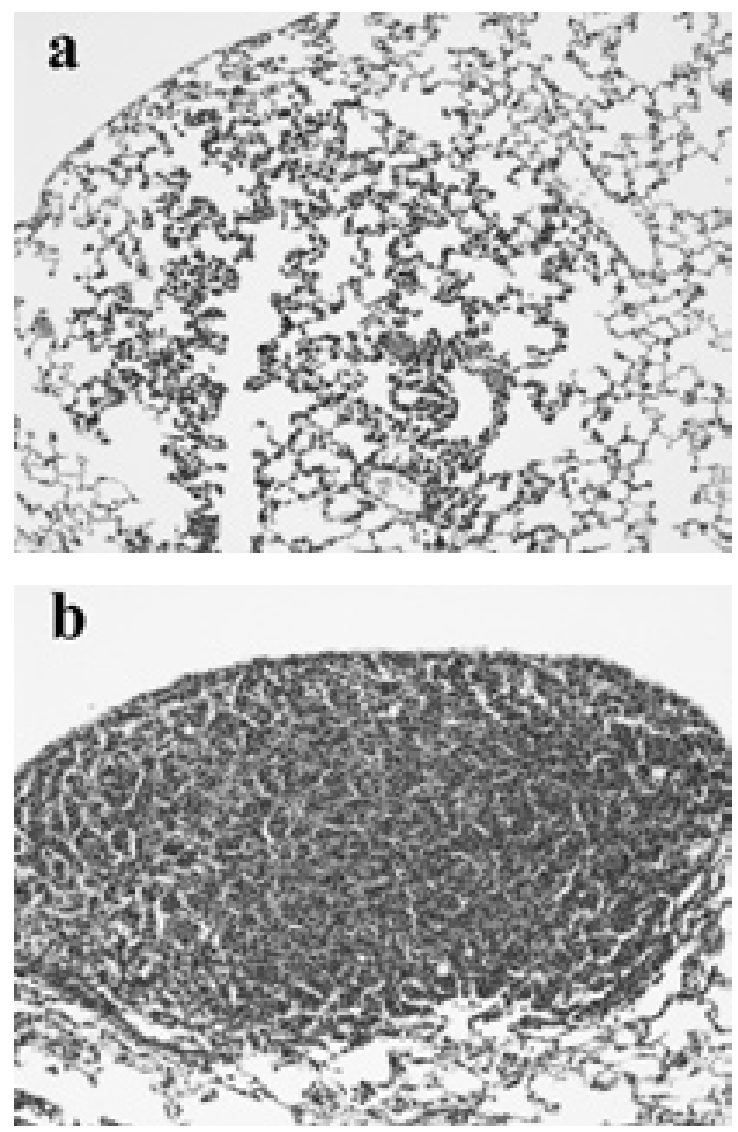
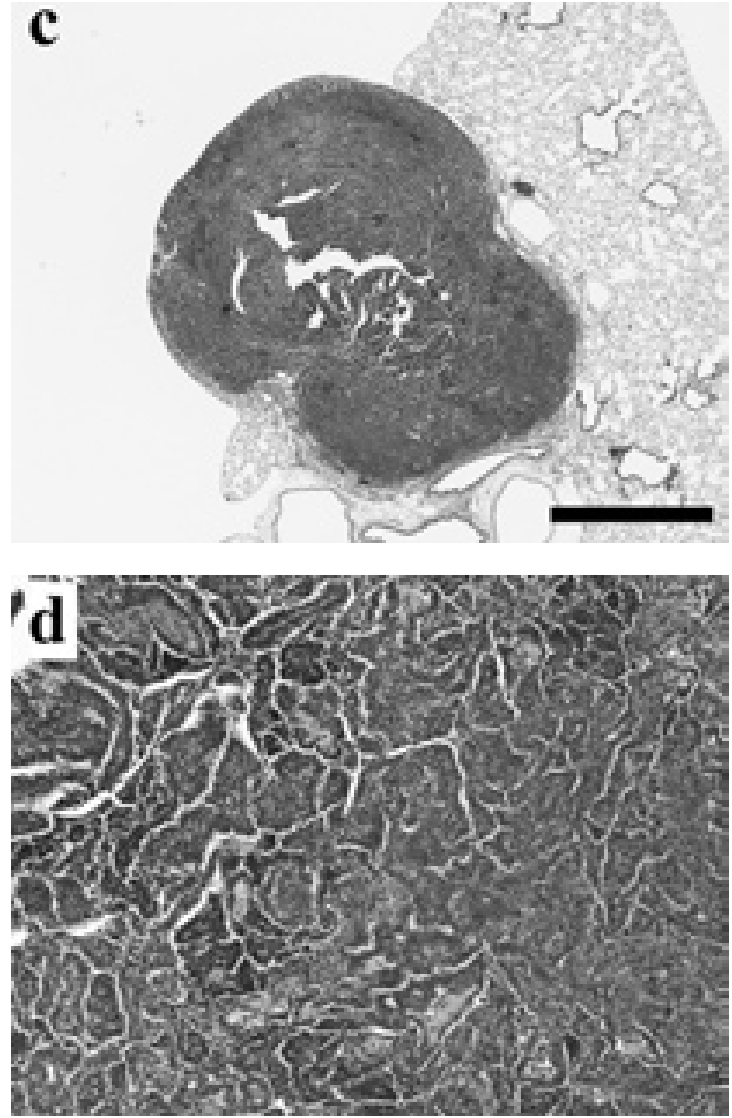

Figure 1. Histopathology of lung proliferative lesions induced by MeIQx (group 2). (a) Hyperplasia, (b) adenoma, (c) and (d) adenocarcinoma. H\&E staining. Original magnification, x10 (a, b and d); x2 (c). Scale bar, $1 \mathrm{~mm}$.

Table IV. Data for CYP1A2 mRNA expression of A/J mice fed diets containing MeIQx and/or high fat.

\begin{tabular}{|c|c|c|c|c|}
\hline & & & Liver & Lung \\
\hline Group & Treatment & No. ${ }^{a}$ & CYP1A2 $2^{b}$ & CYP1A2 \\
\hline 1 & MeIQx 600 ppm + high-fat diet & 10 & $480.3 \pm 105.2^{c}$ & $2.3 \pm 2.8$ \\
\hline 2 & MeIQx 600 ppm + basal diet & 10 & $872.0 \pm 159.6^{\mathrm{d}}$ & $0.9 \pm 1.2$ \\
\hline 3 & High-fat diet & 10 & $134.8 \pm 34.8^{\mathrm{e}}$ & $0.9 \pm 1.3$ \\
\hline 4 & Basal diet & 10 & $233.9 \pm 65.0$ & $1.8 \pm 2.2$ \\
\hline
\end{tabular}

${ }^{a}$ Number of mice examined. ${ }^{b} \mathrm{CYP} 1 \mathrm{~A} 2$ mRNA expression level x103/GAPDH (mean \pm SD). ${ }^{\mathrm{c}}$ Significantly different from groups 2 and 3

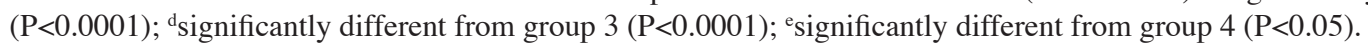

CYP1A2 mRNA levels were analyzed by the Mann-Whitney U test.

\section{Results}

The results for final body and relative organ weights are shown in Table I. Final body weights increased significantly in the high-fat group (group 3) compared to the control (group 4). However, no increase was noted in group 1 which received both MeIQx and high fat. The relative organ weights in the high fat-treated group (group 3) decreased significantly, while the relative liver weights significantly increased in the groups treated with MeIQx (groups 1 and 2).

Lung whitish nodules were detected macroscopically in all of the groups. Lung proliferative lesions, hyperplasias (Fig. 1a), adenomas (Fig. 1b) and carcinomas (Fig. 1c and d) were diagnosed according to the criteria of the 'International Classification of Rodent Tumors: The Mouse' (27), and their numbers were counted under a microscope. Incidences and multiplicities of lung proliferative lesions are summarized in Tables II and III. Values for hyperplasias and adenomas in the MeIQx-treated groups (groups 1 and 2) were significantly 
higher than the respective data for the groups without MeIQx treatment. Both incidences and multiplicities of adenoma + carcinoma, as well as hyperplasia + adenoma + carcinoma (lung proliferative lesions; Table III) were also significantly elevated. Lung carcinomas were observed in 1 mouse in each of the groups (groups 1 and 2) treated with MeIQx. However, the high-fat diet (groups 1 and 3) did not affect the incidences or multiplicities of lung proliferative lesions. Although liver tumors diagnosed as adenomas were observed only in animals treated with MeIQx (groups 1 and 2), their incidences were not significant.

The data for the relative quantification of CYP1A2 mRNAs in the livers and lungs of $\mathrm{A} / \mathrm{J}$ mice are summarized in Table IV. Expression levels in the livers of mice significantly increased by 3.56- and 3.59-fold with MeIQx treatment and significantly decreased with the high-fat diet. However, the expression of CYP1A2 mRNA in the lungs of the MeIQx-treated groups was only $1 / 210$ and $1 / 923$ of that noted in the livers. In the MeIQxuntreated groups, the values were 1/146 in the lungs and 1/133 in the livers, with no inter-group differences in lung CYP1A2 mRNA expression.

\section{Discussion}

Both the previous and current studies showed that MeIQx induces lung tumors in mice (12), supporting the epidemiological finding that MeIQx is associated with lung cancer risk, whereas DiMeIQx and PhIP are not (11). In this study, lung tumors were observed in 1 mouse in each of the groups treated with MeIQx (groups 1 and 2). The experimental duration for a large yield of carcinomas was limited. However, a relatively shorter duration showed that the $\mathrm{A} / \mathrm{J}$ mouse model appears to have advantages in terms of detecting lung the tumorigenic potential of a test compound, such as MeIQx (28).

One epidemiological study has linked a high-fat diet to an increased risk of human lung adenocarcinomas, but specific fats were no longer considered to be significant following adjustment for total fat intake (10). Experimental studies in rodents have shown that $\omega-3$ unsaturated fatty acids may enhance the development of cancer in colon (29), breast (30) and liver (31). We previously noted the promotion of 4NQOinduced pulmonary tumorigenesis in male ICR mice due to a high-fat diet (21). The lack of any enhancing effect of a high concentration of corn oil in the diet in the present study is therefore noteworthy. However, the final body weights in group 1 which was fed both MeIQx and high fat significantly decreased in comparison with group 3 which was fed a diet containing high fat alone, suggesting a complicated influence of the toxicity of MeIQx.

Ohgaki et al (12) previously reported on the high incidence of liver tumor development in mice given a diet containing MeIQx for 84 weeks (12). Liver tumors were also observed in groups receiving MeIQx only, despite the fact that the A/J mouse strain is resistant in terms of hepatocarcinogenesis (32).

It is well known that MeIQx is converted to genotoxic metabolites by liver CYP1A2 $(33,34)$. A previous study showed an increase of about 1.5-2-fold in the expression levels of CYP1A2 mRNA in livers treated with MeIQx (26). Similarly, results of the present study showed a significant increase of
3.56- and 3.59-fold in expression levels of livers when treated with MeIQx. In humans, CYP1A2 has only been detected in the liver (35), and since lung expression was found to be very low, we concluded that the lung tumorigenic potential of MeIQx is mainly due to proximate carcinogens generated in the liver. Following the feeding of mice with a high-fat diet, levels of CYP1A2 mRNA were found to have decreased rather than increased.

In conclusion, we successfully confirmed the lung tumorigenic potential of MeIQx in $\mathrm{A} / \mathrm{J}$ mice over a shorter period of time than the time period used in Ohgaki's experiment (12), although no enhancement by a high-fat diet was evident. Further investigation with more limited exposure to MeIQx may therefore be warranted.

\section{Acknowledgements}

We thank Ms. Kyoko Hosokawa for her expert technical assistance. This study was supported in part by Grants-in-Aid for Cancer Research from the Ministry of Health, Labour and Welfare of Japan.

\section{References}

1. Sugimura T: Studies on environmental chemical carcinogenesis in Japan. Science 233: 312-318, 1986

2. Wakabayashi K, Nagao M, Esumi $\mathrm{H}$ and Sugimura T: Foodderived mutagens and carcinogens. Cancer Res 52: 2092-2098, 1992.

3. Layton DW, Bogen KT, Knize MG, Hatch FT, Johnson VM and Felton JS: Cancer risk of heterocyclic amines in cooked foods: an analysis and implications for research. Carcinogenesis 16: 39-52, 1995.

4. Sinha R, Chow WH, Kulldorff M, Denobile J, Butler J, GarciaClosas M, Weil R, Hoover RN and Rothman N: Well-done, grilled red meat increases the risk of colorectal adenomas. Cancer Res 59: 4320-4324, 1999.

5. Probst-Hensch NM, Sinha R, Longnecker MP, Witte JS, Ingles SA, Frankl HD, Lee ER and Haile RW: Meat preparation and colorectal adenomas in a large sigmoidoscopy-based case-control study in California (United States). Cancer Causes Control 8: 175-183, 1997.

6. Zheng W, Gustafson DR, Sinha R, Cerhan JR, Moore D, Hong CP, Anderson KE, Kushi LH, Sellers TA and Folsom AR: Well-done meat intake and the risk of breast cancer. J Natl Cancer Inst 90: 1724-1729, 1998.

7. Sinha R, Gustafson DR, Kulldorff M, Wen WQ, Cerhan JR and Zheng W: 2-amino-1-methyl-6-phenylimidazo[4,5-b]pyridine, a carcinogen in high-temperature-cooked meat and breast cancer risk. J Natl Cancer Inst 92: 1352-1354, 2000

8. De Stefani E, Boffetta P, Mendilaharsu M, Carzoglio J and Deneo-Pellegrini H: Dietary nitrosamines, heterocyclic amines and risk of gastric cancer: a case-control study in Uruguay. Nutr Cancer 30: 158-162, 1998.

9. Sinha R, Kulldorff M, Curtin J, Brown CC, Alavanja MC and Swanson CA: Fried, well-done red meat and risk of lung cancer in women (United States). Cancer Causes Control 9: 621-630, 1998.

10. De Stefani E, Brennan P, Boffetta P, Mendilaharsu M, DeneoPellegrini H, Ronco A, Olivera L and Kasdorf H: Diet and adenocarcinoma of the lung: a case-control study in Uruguay. Lung Cancer 35: 43-51, 2002.

11. Sinha R, Kulldorff M, Swanson CA, Curtin J, Brownson RC and Alavanja MC: Dietary heterocyclic amines and the risk of lung cancer among Missouri women. Cancer Res 60: 3753-3756, 2000.

12. Ohgaki H, Hasegawa H, Suenaga M, Sato S, Takayama S and Sugimura T: Carcinogenicity in mice of a mutagenic compound, 2-amino-3,8-dimethylimidazo[4,5-f]quinoxaline (MeIQx) from cooked foods. Carcinogenesis 8: 665-668, 1987. 
13. Sugimura T: Nutrition and dietary carcinogens. Carcinogenesis 21: 387-395, 2000.

14. Hinds MW, Kolonel LN, Lee J and Hankin JH: Dietary cholesterol and lung cancer risk among men in Hawaii. Am J Clin Nutr 37: 192-193, 1983.

15. Reddy BS, Cohen LA, McCoy GD, Hill P, Weisburger JH and Wynder EL: Nutrition and its relationship to cancer. Adv Cancer Res 32: 237-345, 1980.

16. Wynder EL, Kajitani T, Ishikawa S, Dodo H and Takano A: Environmental factors of cancer of the colon and rectum. II. Japanese epidemiological data. Cancer 23: 1210-1220, 1969.

17. Sugimura T, Wakabayashi $K$, Nakagama $H$ and Nagao $M$ : Heterocyclic amines: mutagens/carcinogens produced during cooking of meat and fish. Cancer Sci 95: 290-299, 2004.

18. Knekt P, Seppanen R, Jarvinen R, Virtamo J, Hyvonen L, Pukkala E and Teppo L: Dietary cholesterol, fatty acids and the risk of lung cancer among men. Nutr Cancer 16: 267-275, 1991.

19. De Stefani E, Deneo-Pellegrini H, Mendilaharsu M, Carzoglio JC and Ronco A: Dietary fat and lung cancer: a case-control study in Uruguay. Cancer Causes Control 8: 913-921, 1997.

20. Alavanja MC, Brown CC, Swanson C and Brownson RC: Saturated fat intake and lung cancer risk among non-smoking women in Missouri. J Natl Cancer Inst 85: 1906-1916, 1993.

21. Imaida K, Sato H, Okamiya H, Takahashi M and Hayashi Y: Enhancing effect of high fat diet on 4-nitroquinoline 1-oxideinduced pulmonary tumorigenesis in ICR male mice. Jpn J Cancer Res 80: 499-502, 1989.

22. Yamazoe Y, Abu-Zeid M, Manabe S, Toyama S and Kato R: Metabolic activation of a protein pyrolysate promutagen 2-amino3,8-dimethylimidazo[4,5-f]quinoxaline by rat liver microsomes and purified cytochrome P-450. Carcinogenesis 9: 105-109, 1988.

23. Turesky RJ, Constable A, Richoz J, Varga N, Markovic J, Martin MV and Guengerich FP: Activation of heterocyclic aromatic amines by rat and human liver microsomes and by purified rat and human cytochrome P450 1A2. Chem Res Toxicol 11: 925-936, 1998.

24. Davis CD, Schut HA and Snyderwine EG: Enzymatic phase II activation of the N-hydroxylamines of IQ, MeIQx and PhIP by various organs of monkeys and rats. Carcinogenesis 14 2091-2096, 1993
25. Jaiswal AK, Nebert DW, McBride OW and Gonzalez FJ: Human P(3)450: cDNA and complete protein sequence, repetitive Alu sequences in the 3 ' nontranslated region and localization of gene to chromosome 15. J Exp Pathol 3: 1-17, 1987.

26. Fujita K, Ohnishi T, Sekine K, Iigo $M$ and Tsuda H: Downregulation of 2-amino-3,8-dimethylimidazo[4,5-f]quinoxaline (MeIQx)-induced CYP1A2 expression is associated with bovine lactoferrin inhibition of MeIQx-induced liver and colon carcinogenesis in rats. Jpn J Cancer Res 93: 616-625, 2002.

27. Dungworth DL, Rittinghausen S, Schwartz L, Harkema JR, Hayashi Y, Kittel B, Lewis D, Miller RA, Mohr U, Morgan KT, Rehm S and Slayter MV: Respiratory System and Mesothelium. International Classification of Rodent Tumors: The Mouse. WHO. International Agency for Research on Cancer, New York, 2001.

28. Shimkin MB and Stoner GD: Lung tumors in mice: application to carcinogenesis bioassay. Adv Cancer Res 21: 1-58, 1975.

29. Reddy BS: Dietary fat and colon cancer: animal model studies. Lipids 27: 807-813, 1992.

30. Cohen LA, Thompson DO, Maeura Y, Choi K, Blank ME and Rose DP: Dietary fat and mammary cancer. I. Promoting effects of different dietary fats on N-nitrosomethylurea-induced rat mammary tumorigenesis. J Natl Cancer Inst 77: 33-42, 1986.

31. Rahman KM, Sugie S, Okamoto K, Watanabe T, Tanaka T and Mori H: Modulating effects of diets high in omega-3 and omega-6 fatty acids in initiation and postinitiation stages of diethylnitrosamine-induced hepatocarcinogenesis in rats. Jpn J Cancer Res 90: 31-39, 1999.

32. Dragani TA, Manenti G and Della Porta G: Quantitative analysis of genetic susceptibility to liver and lung carcinogenesis in mice. Cancer Res 51: 6299-6303, 1991.

33. Boobis AR, Lynch AM, Murray S, De la Torre R, Solans A, Farre M, Segura J, Gooderham NJ and Davies DS: CYP1A2catalyzed conversion of dietary heterocyclic amines to their proximate carcinogens is their major route of metabolism in humans. Cancer Res 54: 89-94, 1994.

34. Rich KJ, Murray BP, Lewis I, Rendell NB, Davies DS, Gooderham NJ and Boobis AR: N-hydroxy-MeIQx is the major microsomal oxidation product of the dietary carcinogen MeIQx with human liver. Carcinogenesis 13: 2221-2226, 1992.

35. Landi MT, Sinha R, Lang NP and Kadlubar FF: Human cytochrome P450 1A2. IARC Sci Publ: 173-195, 1999. 